\title{
Estresse por deficiência hídrica em genótipos de Brachiaria brizantha
}

\author{
Hydric deficiency in genotypes of Brachiaria brizantha
}

\begin{abstract}
Cristiana de Gaspari Pezzopane ${ }^{\mathrm{I}}$ Patrícia Menezes Santos ${ }^{\mathrm{I}}$ Pedro Gomes da Cruz ${ }^{\mathrm{II}}$ Jonas Altoé ${ }^{\text {Felipe Azevedo Ribeiro }}{ }^{I}$ Cacilda Borges do Valle ${ }^{I I I}$
\end{abstract}

\section{RESUMO}

O experimento foi desenvolvido em casa de vegetação na Embrapa Pecuária Sudeste, utilizando acessos de Brachiaria brizantha. O delineamento experimental foi o de blocos ao acaso, com arranjo fatorial $2 \times 4$, sendo dois tratamentos (com e sem déficit hídrico) e quatro genótipos. $O$ grupo de genótipos avaliado foi formado pelas cultivares 'BRS Piatã', 'Marandu', 'Xaraés' $e$ 'BRS Paiaguás', sendo o experimento realizado durante o mês de julho de 2008. As variáveis analisadas foram massa seca total massa seca de parte aérea, massa seca de raiz, massa seca de colmo, massa seca de folha, taxa de alongamento foliar, área foliar, área foliar especifica. $O$ estresse por deficiência hídrica exerceu efeito negativo em todas as características estudadas e em todos os acessos avaliados. A cultivar 'BRS Piatã' foi o genótipo que menos apresentou alteração entre os tratamentos com e sem déficit hídrico, indicando portanto, tolerância dessa cultivar em relação ao estresse por falta de água no solo nessas condições experimentais.

Palavras-chave: estresse abiótico, acessos, taxa de alongamento, área foliar.

\section{ABSTRACT}

The experiment was conducted in a greenhouse at Embrapa Southeast Livestock, using Brachiaria brizantha accessions. The experimental design was fully randomized blocks with a $2 \times 4$ factorial arrangement, with two treatments (with and without water deficit) and four genotypes. The group evaluated was formed by genotypes 'BRS Piatã', 'Marandu', 'Xaraés' and 'BRS Paiaguás'. The experiment was conducted during the month of July 2008. The variables analyzed were dry mass of total plant, shoot mass, leaves, stems and roots, leaf elongation rate, leaf area and specific leaf area. The water deficit stress exerted negative effect on all characteristics studied and in all accessions. 'BRS Piatã' was the genotype that showed less change between treatments with and without water deficit, thus indicating tolerance of this cultivar in relation to water stress in the soil under these experimental conditions.

Key words: abiotic stress, accession, elongation rate, leaf area.

\section{INTRODUÇÃO}

O Brasil se baseia na utilização de pastagens para a exploração pecuária, sendo cerca de 170 milhões de hectares cultivados por plantas forrageiras (IBGE, 2006). Dentro dessa extensão do território usado para a prática pecuária, existe grande diversidade nas condições de plantio de forrageiras, incluindo áreas alagadas ou encharcadas, com baixo índice de precipitação, baixa fertilidade de solo, além de áreas aptas ao cultivo. Portanto, devido ao cultivo de plantas forrageiras em áreas marginais, há a necessidade de estudos que avaliem e identifiquem genótipos com características de tolerância a estresses abióticos. Das espécies forrageiras cultivadas no Brasil, o gênero Brachiaria é o mais utilizado, devido ao fato de apresentar alta produção de matéria seca, boa adaptabilidade, facilidade de estabelecimento, persistência, bom valor nutritivo, poucos problemas com doenças, além de apresentar bom crescimento durante a maior parte do ano, inclusive no período seco (COSTA et al., 2005).

O gênero Brachiaria compreende cerca de 100 espécies originárias, principalmente do

\footnotetext{
${ }^{\mathrm{I} E m b r a p a}$ Pecuária Sudeste, Rodovia Washington Luiz, Km 234, s/nº, Fazenda Canchim, CP 339, 13560-970, São Carlos, SP, Brasil.

E-mail: cristiana.gaspari@gmail.com.*Autor para correspondência

"Embrapa Rondônia, Porto Velho, RO, Brasil.

IIIEmbrapa Gado de Corte, Campo Grande, MS, Brasil. 
continente Africano (KELLER-GREIN et al., 1996). A espécie mais plantada no Brasil atualmente é a Brachiaria brizantha (PEDREIRA et al., 2009), com acessos coletados em áreas com grande amplitude na precipitação pluvial anual variando de 590 a 2.770 e com períodos de seca de 0 a 7 meses (KELLERGREIN et al., 1996). As principais cultivares da espécie B. brizantha são 'Marandu', 'BRS Piatã', 'La Libertad' e 'Xaraés', apresentando grande potencial de adaptação às condições tropicais brasileiras (VALLE et al., 2011).

Em plantas, o estresse abiótico desencadeia uma série de respostas a partir de alterações da expressão gênica e do metabolismo celular (BRAY et al., 2000), causando diminuição do potencial osmótico. Consequentemente, reduzindo o turgor celular ocorre uma diminuição acentuada na taxa de expansão foliar e taxa geral de crescimento da planta (DUQUE et al., 2013).

$\mathrm{Na}$ eficiência do uso da água (EUA) ou na tolerância a deficiência hídrica, a planta utiliza mecanismos fisiológicos e anatômicos que retardam a desidratação comouma diminuição da atividadecelular para a manutenção do potencial osmótico, como uma tentativa para conter a desidratação celular (ZHENG et al., 2000; DUQUE et al., 2013). Entre os genótipos existe grande variabilidade quanto a essa característica de sobreviver em condições de deficiência hídrica. As principais mudanças que uma planta submetida ao estresse hídrico apresenta são: menor crescimento, redução da área foliar, maior crescimento do sistema radicular, enrolamento das folhas, redução de turgor, fechamento dos estômatos, abscisão floral e alteração na permeabilidade da cutícula (XOCONOSTLECAZARES et al., 2010; BASTOS et al., 2011; VARSHNEY et al., 2011; SILVA et al., 2011). Todas essas alterações citadas anteriormente limitam a produtividade, ocasionando danos ao produtor.

O desenvolvimento de cultivares tolerantes ao déficit hídrico e mais eficientes no uso da água é uma das alternativas para o cultivo em ambientes com restrições hídricas. Portanto, o objetivo deste trabalho foi comparar duas condições de cultivo em relação à disponibilidade hídrica, deficiência e condições ideais, em diferentes genótipos de Brachiaria brizantha.

\section{MATERIAL E MÉTODOS}

Os experimentos foram desenvolvidos em casa-de-vegetação na Embrapa Pecuária Sudeste, localizada no município de São Carlos, estado de São Paulo. O material vegetal usado de Brachiaria brizantha foram as cultivares 'BRS
Piatã', 'Marandu', 'Xaraés' e 'BRS Paiaguás'. O experimento foi realizado durante o mês de julho do ano de 2008. Os acessos de Brachiaria brizantha utilizados no experimento foram provenientes do banco de germoplasma mantido pela Embrapa Gado de Corte, localizada na cidade de Campo Grande, MS. O delineamento experimental foi de blocos completos ao acaso em arranjo fatorial 4x2 (quatro acessos e duas condições hídricas), com quatro repetições. Os blocos foram alocados de acordo com o gradiente de umidade presente na estufa.

Os vasos foram preenchidos com $7 \mathrm{~kg}$ de solo seco ao ar com as seguintes características químicas e físicas: $\mathrm{pH} \mathrm{H}_{2} \mathrm{O} 6,6 ; \mathrm{pH} \mathrm{CaCl}_{2} 5,7$; M.O $22 \mathrm{~g} \mathrm{dm}^{-3}$; P resina $27 \mathrm{mg} \mathrm{dm}^{-3}$; $\mathrm{K} 3,3 \mathrm{mmolc} \mathrm{dm}^{-3}$; Ca $25 \mathrm{mmolc} \mathrm{dm}^{-3} ; \mathrm{Mg} 9$ mmolc $\mathrm{dm}^{-3} ; \mathrm{H}+\mathrm{Al} 22 \mathrm{mmol}$ $\mathrm{dm}^{-3}$; Al 0mmolc $\mathrm{dm}^{-3}$; CTC 60mmolc $\mathrm{dm}^{-3}$; S $37 \mathrm{mmolc} \mathrm{dm}^{-3}$; V 62\%; $\mathrm{m} \mathrm{0 \%}$; (Ca+Mg) / K-10; S.SO4 4mg dm ${ }^{-3}$; B 0,16mg dm ${ }^{-3}$; Cu 2,2mg dm $\mathrm{m}^{-3}$;

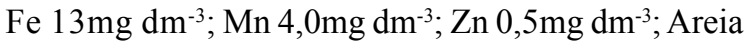
$541 \mathrm{~g} \mathrm{~kg}^{-1}$; Argila $389 \mathrm{~g} \mathrm{~kg}^{-1}$; Silte $70 \mathrm{~g} \mathrm{~kg}^{-1}$.

Antes de ser colocado nos vasos, o solo foi peneirado e corrigido com calcário. A dose de calcário foi calculada pelo método da saturação por bases com o objetivo de atingir 70\% de saturação. Para promover a reação do calcário, os vasos foram irrigados até $80 \%$ da capacidade de campo por um período de 25 dias. Em seguida, foi feita a adubação com: $150 \mathrm{mg} \mathrm{kg}^{-1} \mathrm{~N} ; 200 \mathrm{mg} \mathrm{kg}^{-1} \mathrm{P} ; 75 \mathrm{mg} \mathrm{kg}^{-1} \mathrm{~K}$; $0,5 \mathrm{mg} \mathrm{kg}^{-1} \mathrm{~B} ; 1,5 \mathrm{mg} \mathrm{kg}^{-1} \mathrm{Cu} ; 3 \mathrm{mg} \mathrm{kg}^{-1} \mathrm{Mn}$ e $5 \mathrm{mg} \mathrm{kg}^{-1}$ Zn (MALAVOLTA, 1980).

O plantio foi feito diretamente nos vasos e, quando as plantas apresentavam três folhas completamente expandidas, foi feito um desbaste deixando cinco plantas por vaso. Após a completa expansão da sexta folha, a irrigação dos vasos do tratamento com estresse hídrico foi suspensa, enquanto os vasos do tratamento testemunha (sem estresse hídrico) continuaram sendo irrigados até $90 \%$ da capacidade de campo. A coleta final foi feita sete dias após o início do tratamento.

As avaliações incluíram as variáveis taxa de alongamento foliar ( $\mathrm{cm}$ perfilho $\mathrm{dia}^{-1}$ ), massa seca de hastes $\left(\mathrm{g} \mathrm{vaso}^{-1}\right)$, massa seca de folhas $\left(\mathrm{g}_{\text {vaso }}{ }^{-1}\right)$, massa seca de raízes ( $\mathrm{g}^{-1}$ vaso), massa seca de parte aérea ( $\mathrm{g}$ vaso $\left.^{-1}\right)$, massa seca total $\left(\mathrm{g}\right.$ vaso $\left.{ }^{-1}\right)$, área foliar $\left(\mathrm{cm}^{2}\right.$ vaso $\left.^{-1}\right)$ e área foliar específica $\left(\mathrm{cm}^{2} \mathrm{~g}^{-1}\right)$.

A taxa de alongamento foliar foi avaliada a partir do aparecimento da sexta folha de um perfilho, identificado com fios de arame coloridos, em duas plantas porvaso.Asavaliações foramfeitas diariamente medindo-se o comprimento da ponta da folha até a lígula da folha mais nova completamente expandida. 
No dia da coleta, a parte aérea das plantas foi cortada e separada em lâminas foliares e haste e pesadas. As lâminas foliares foram imediatamente encaminhadas para a determinação da área foliar com o auxílio do integrador de área foliar (LI-COR modelo LI-3100C). As raízes foram lavadas em água corrente com o auxílio de peneira de $1 \mathrm{~mm}$ e em seguida pesadas. A massa seca de lâminas foliares, hastes e raízes foi determinada após a secagem em estufa de circulação forçada de ar a $65^{\circ} \mathrm{C}$ por 48 horas. A área foliar específica é a relação da área foliar total $\left(\mathrm{cm}^{2}\right)$ pela massa seca de folhas (g).

Os dados foram submetidos a análise de variância pelo procedimento GLM do SAS (LITTELL et al., 2006) considerando como fontes de variação os efeitos de bloco, de acessos, de condição hídrica e da interação entre acessos e condição hídrica. $\mathrm{Na}$ comparação múltipla das médias foi adotado o teste de Tukey, em nível de significância de 5\%. Para a análise de agrupamento foi utilizado o programa Past (HAMMER et al., 2001).

\section{RESULTADOS E DISCUSSÃO}

A baixa umidade no solo causa a menor produção ou até mesmo a morte das plantas. Observouse nesse experimento que o estresse hídrico determinou redução de todas as características avaliadas, em todos os acessos estudados (Tabelas 1, 2, 3 e 4).

A taxa de alongamento foliar apresentou maior redução nos genótipos Marandu (94\%) e Xaraés $(93 \%)$ e a menor redução foi observada na cultivar 'BRS Piatã' (62\%), seguida por 'BRS Paiaguás' (81\%) (Tabela 2). Para a variável área foliar específica, as reduções foram ao redor de $50 \%$ para todos os materiais estudados, sendo a menor redução apresentada por 'BRS Paiaguás' (42\%) (Tabela 1). Já para área foliar (cm2/vaso), as perdas foram ainda maiores, $70 \%$ em média, chegando a 78\% em Xaraés,
75\% em 'Marandu', 74\% em 'BRS Piatã' e 73\% em 'BRS Paiaguás' (Tabela 1).

Para as variáveis taxa de alongamento e área foliar, houve diferença significativa entre os genótipos (Tabelas 1 e 2). A cultivar 'BRS Piatã' apresentou a maior taxa de alongamento e a menor área foliar e a cultivar 'Marandu' obteve a menor taxa de alongamento e a maior área foliar. A baixa disponibilidadedeáguanosoloocasionaadesidratação, redução do crescimento, aceleração da senescência dos tecidos, comprometendo o crescimento por reduzir as taxas de expansão foliar e fotossíntese (LUDLOW \& NG, 1976; BENNETT \& SULLIVAN, 1981).

A massa seca total foi maior nas plantas sem estresse hídrico (Tabela 4). A maior redução na massa seca total em função do estresse hídrico foi observada na cultivar 'Xaraés' (49\%), seguido de Marandu (41\%) e BRS Paiaguás (40\%). A cultivar 'BRS Piatã' apresentou a menor redução na massa seca total em função do déficit hídrico (28\%).

A massa seca de parte aérea foi 49 a $45 \%$ menor nos tratamentos com estresse hídrico, resultante da redução de massa seca de haste e de folhas (Tabela 3). A maior redução na massa seca de raiz em função do déficit hídrico foi observada na cultivar 'Xaraés' (52\%), seguido por 'Marandu' (34\%) e 'BRS Paiaguás' (23\%). Apesar do efeito da interação acesso $\mathrm{x}$ condição hídrica sobre a massa seca de raiz não ser significativo $(\mathrm{P}=0,1429)$, observa-se que a massa de raiz da cultivar 'BRS Piatã' foi semelhante nos dois tratamentos. As variáveis analisadas, massa seca total e massa seca de raiz, não apresentaram diferenças significativas entre genótipos. Porém, para as características massa seca de parte aérea, de haste e de folha os genótipos diferiram entre si, apesar da porcentagem de redução ter ficado ao redor de 40 a $50 \%$. MELO et al. (2003) observaram que a massa seca de parte aérea de $\boldsymbol{B}$. brizantha

Tabela 1 - Área foliar e área foliar específica de plantas de quatro acessos de Brachiaria brizantha submetidas ou não ao estresse por déficit hídrico. Os números representam a média \pm erro padrão da média.

\begin{tabular}{|c|c|c|c|c|c|c|}
\hline Genótipo & Estresse & $\begin{array}{l}\text { Testemunha } \\
\text { foliar }\left(\mathrm{cm}^{2} \text { vase }\right.\end{array}$ & Média & Estresse & $\begin{array}{l}\text { Testemunha } \\
\text { ar específica }\end{array}$ & Média \\
\hline Piatã & $260,6 \pm 24,7$ & $1003,5 \pm 89,3$ & $632,1^{\mathrm{B}}$ & $80,6 \pm 4,2$ & $167,8 \pm 1,3$ & $125,8^{\mathrm{A}}$ \\
\hline Paiaguás & $398,4 \pm 13,6$ & $1448,8 \pm 257,5$ & $923,6^{\mathrm{AB}}$ & $95,9 \pm 4,7$ & $165,0 \pm 30,5$ & $130,4^{\mathrm{A}}$ \\
\hline Marandu & $389,4 \pm 23,2$ & $1558,2 \pm 188,9$ & $973,8^{\mathrm{A}}$ & $101,9 \pm 5,8$ & $208,2 \pm 2,1$ & $155,0^{\mathrm{A}}$ \\
\hline Xaraés & $332,6 \pm 8,9$ & $1506,0 \pm 55,9$ & $913,3^{\mathrm{AB}}$ & $87,4 \pm 1,4$ & $202,6 \pm 10,2$ & $145,0^{\mathrm{A}}$ \\
\hline Média & $334,1^{\mathrm{b}}$ & $1319,1^{\mathrm{a}}$ & & $89,2^{\mathrm{b}}$ & $183,0^{\mathrm{a}}$ & \\
\hline
\end{tabular}

Médias seguidas da mesma letra, maiúscula na coluna e minúscula na linha, não diferem entre si pelo teste de Tukey (P>0,05).

Ciência Rural, v.45, n.5, mai, 2015. 
Tabela 2 - Taxa de alongamento foliar de plantas de quatro acessos de Brachiaria brizantha submetidas ou não ao estresse por déficit hídrico. Os números representam a média \pm erro padrão da média.

Genótipo - Taxa de alongamento foliar $\left(\mathrm{cm}\right.$ perfilho $\left.{ }^{-1} \mathrm{dia}^{-1}\right)$ -

\begin{tabular}{llcl} 
& Estresse & Testemunha & Média \\
\hline Piatã & $2,7 \pm 0,4$ & $7,2 \pm 0,2$ & $4,9^{\mathrm{A}}$ \\
Paiaguás & $1,2 \pm 0,4$ & $6,4 \pm 0,4$ & $3,8^{\mathrm{AB}}$ \\
Marandu & $0,3 \pm 0,1$ & $4,9 \pm 0,6$ & $2,6^{\mathrm{B}}$ \\
Xaraés & $0,5 \pm 0,1$ & $6,9 \pm 0,3$ & $3,7^{\mathrm{AB}}$ \\
Média & $1,5^{\mathrm{b}}$ & $6,4^{\mathrm{a}}$ & \\
\hline
\end{tabular}

Médias seguidas da mesma letra, maiúscula na coluna e minúscula na linha, não diferem entre si pelo teste de Tukey $(\mathrm{P}>0,05)$.

em solo mantido a $60 \%$ da capacidade de campo foi cerca de $30 \%$ menor que daquelas cultivadas em solo mantido a $80 \%$ da capacidade de campo, em comparação com a espécie B. decumbens.

Emmassa seca da parte aérea e massa seca de folhas, a maior média foi observada em 'BRS Paiaguás' e a menor em 'BRS Piatã' e para massa seca de haste o maior valor foi alcançado por 'BRS Piatã', seguido por 'BRS Paiaguás', 'Marandu' e 'Xaraés' (Tabela 3).

Nesse experimento, portanto, foi observada diferença significativa entre tratamentos de condições hídricas para todas as variáveis analisadas. Entre genótipos, cinco dessas características apresentaram diferença significativa, taxa de alongamento foliar, área foliar, massa seca de parte aérea, massa seca de haste e massa seca de folha. Mas, dentre essas cinco apenas taxa de alongamento foliar apresentou diferença significativa para porcentagem de redução do genótipo, sendo portanto a condição de estresse com taxa bastante reduzida em relação a testemunha.

Massa seca total e massa seca de raiz, apesar de não apresentarem diferença significativa entre genótipos, quando se considera porcentagem de redução, observa-se amplitude acentuada nos valores. Em massa seca total a cultivar 'BRS Piatã' reduziu apenas $28 \%$ em condição de seca e o restante dos materiais estudados ficaram ao redor de $40 \%$ de redução, chegando a $49 \%$ na cultivar 'Xaraés'. Para massa seca de raiz a cultivar 'BRS Piatã' não apresentou redução, seguida por 'BRS Paiaguás' (23\%), 'Marandu' (34\%) e 'Xaraés' (52\%).

Considerando apenas a porcentagem de redução para as variáveis taxa de alongamento foliar, massa seca total e massa seca de raiz, a cultivar 'BRS Piatã' foi o genótipo com menores danos sofridos pelo estresse causado pela deficiência hídrica. Nessa situação, os demais genótipos, 'BRS Paiaguás', 'Marandu' e 'Xaraés' não apresentaram diferenças significativas entre eles.

$\mathrm{Na}$ figura 1, observa-se que a cultivar 'BRS Piatã' é a mais distante geneticamente das demais, portanto essa diferença é muito pequena, indicando grande similaridade entre os genótipos de Brachiaria brizantha avaliados nesse experimento, tanto em condiçãodedeficiênciahídricaquantonastestemunhas.

Esses resultados indicam que os genótipos de Brachiaria brizantha estudados nesse experimento apresentam comportamento semelhante quando colocados em situação de seca e entre eles a cultivar 'BRS Piatã' se destaca com menor porcentagem de redução. Nesse estudo, as cultivares se comportaram

Tabela 3 - Massa seca de parte aérea, raízes, haste e folhas de plantas de quatro acessos de Brachiaria brizantha submetidas ou não ao estresse por déficit hídrico. Os números representam a média \pm erro padrão da média.

\begin{tabular}{|c|c|c|c|c|c|c|}
\hline Genótipo & Estresse & Testemunha & Média & Estresse & Testemunha & Média \\
\hline Piatã & $5,8 \pm 0,4$ & $10,6 \pm 0,7$ & $8,2^{\mathrm{B}}$ & $5,9 \pm 2,0$ & $5,5 \pm 1,0$ & $5,7^{\mathrm{A}}$ \\
\hline Paiaguás & $7,9 \pm 0,3$ & $15,4 \pm 1,0$ & $11,7^{\mathrm{A}}$ & $6,0 \pm 0,5$ & $7,8 \pm 0,9$ & $6,9^{\mathrm{A}}$ \\
\hline Marandu & $7,1 \pm 0,3$ & $13,3 \pm 1,5$ & $10,2^{\mathrm{AB}}$ & $6,8 \pm 0,4$ & $10,3 \pm 1,4$ & $8,5^{\mathrm{A}}$ \\
\hline Xaraés & $6,9 \pm 0,2$ & $12,9 \pm 0,5$ & $10,0^{\mathrm{AB}}$ & $5,4 \pm 0,6$ & $11,1 \pm 1,6$ & $8,2^{\mathrm{A}}$ \\
\hline \multirow[t]{2}{*}{ Média } & $6,9^{\mathrm{b}}$ & $12,7^{\mathrm{a}}$ & & $6,2^{\mathrm{b}}$ & $8,4^{\mathrm{a}}$ & \\
\hline & \multicolumn{3}{|c|}{ 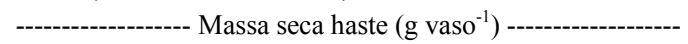 } & ---------- & eca de folha $(\xi$ & ------- \\
\hline Piatã & $2,6 \pm 0,2$ & $4,7 \pm 0,2$ & $5,6^{\mathrm{C}}$ & $3,2 \pm 0,2$ & $6,0 \pm 0,5$ & $4,6^{\mathrm{B}}$ \\
\hline Paiaguás & $3,7 \pm 0,1$ & $6,4 \pm 0,4$ & $5,1^{\mathrm{A}}$ & $4,2 \pm 0,2$ & $9,0 \pm 0,7$ & $6,6^{\mathrm{A}}$ \\
\hline Marandu & $3,3 \pm 0,1$ & $5,8 \pm 0,6$ & $4,6^{\mathrm{AB}}$ & $3,8 \pm 0,2$ & $7,5 \pm 0,9$ & $5,7^{\mathrm{AB}}$ \\
\hline Xaraés & $3,1 \pm 0,2$ & $5,4 \pm 0,2$ & $4,3^{\mathrm{BC}}$ & $3,8 \pm 0,1$ & $7,5 \pm 0,3$ & $5,6^{\mathrm{AB}}$ \\
\hline Média & $3,1^{\mathrm{b}}$ & $5,4^{\mathrm{a}}$ & & $3,7^{\mathrm{b}}$ & $7,2^{\mathrm{a}}$ & \\
\hline
\end{tabular}

Médias seguidas da mesma letra, maiúscula na coluna e minúscula na linha, não diferem entre si pelo teste de Tukey (P>0,05). 
Tabela 4 - Massa seca total de plantas de quatro acessos de Brachiaria brizantha submetidas ou não ao estresse por déficit hídrico. Os números representam a média \pm erro padrão da média.

\begin{tabular}{|c|c|c|c|}
\hline \multirow[t]{2}{*}{ Genótipo } & \multicolumn{3}{|c|}{ 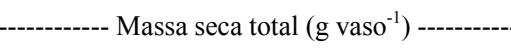 } \\
\hline & Estresse & Testemunha & Média \\
\hline Piatã & $11,6 \pm 2,2$ & $16,1 \pm 0,9$ & $13,9^{\mathrm{A}}$ \\
\hline Paiaguás & $13,9 \pm 0,5$ & $23,2 \pm 1,9$ & $18,6^{\mathrm{A}}$ \\
\hline Marandu & $13,9 \pm 0,7$ & $23,6 \pm 2,6$ & $18,7^{\mathrm{A}}$ \\
\hline Xaraés & $12,3 \pm 0,7$ & $24,0 \pm 2,0$ & $18,1^{\mathrm{A}}$ \\
\hline Média & $13,1^{\mathrm{b}}$ & $21,0^{\mathrm{a}}$ & \\
\hline
\end{tabular}

Médias seguidas da mesma letra, maiúscula na coluna e minúscula na linha, não diferem entre si pelo teste de Tukey $(\mathrm{P}>0,05)$.

com relativa tolerância a seca, não apresentando acentuadas reduções nos índices avaliados, com exceção da taxa de alongamento foliar, que chegou a 94\% na cultivar 'Marandu'.

Essa tolerância observada pode ser proveniente da espécie em estudo, como os resultados obtidos por MATTOS et al (2005), em estudo comparando diferentes espécies do gênero Brachiaria, observaram que a $\boldsymbol{B}$. brizantha foi a espécie de maior tolerância ao déficit hídrico, em decorrência da menor sensibilidade de seus estômatos ao estresse, do menor comprometimento de suas taxas de fotossíntese e transpiração, das mais altas taxas de alongamento, das baixas taxas de senescência de suas lâminas foliares e de sua expressiva produção de raízes. Avaliando três espécies comerciais (B. decumbens cv. 'Basilisk', B. brizantha cv. 'Marandu' e $\boldsymbol{B}$. mutica) e três acessos (B. brizantha B-11, B. humidicola cv. 'Tupi' e B. dictyoneura) de Brachiaria, MATTOS et al. (2005) observaram que sob déficit hídrico, o índice de área foliar foi mais alto apenas nos genótipos de B. brizantha estudados, 'Marandu' e 'B11'. Também estudando diferentes espécies do gênero Brachiaria, GUENNI et al. (2002) observaram que a taxa de utilização de água foi mais elevada na $\boldsymbol{B}$. brizantha, B. decumbens e B. mutica $(0,251 \mathrm{~L} / \mathrm{dia})$ que na $\boldsymbol{B}$. humidicola (CIAT 679) e B. dictyoneura (CIAT 6133) $\left(0,131 \mathrm{~L} \mathrm{dia}^{-1}\right)$, concluindo que as três primeiras espécies são mais indicadas para curtos períodos de seca e as demais para prolongados períodos de seca.

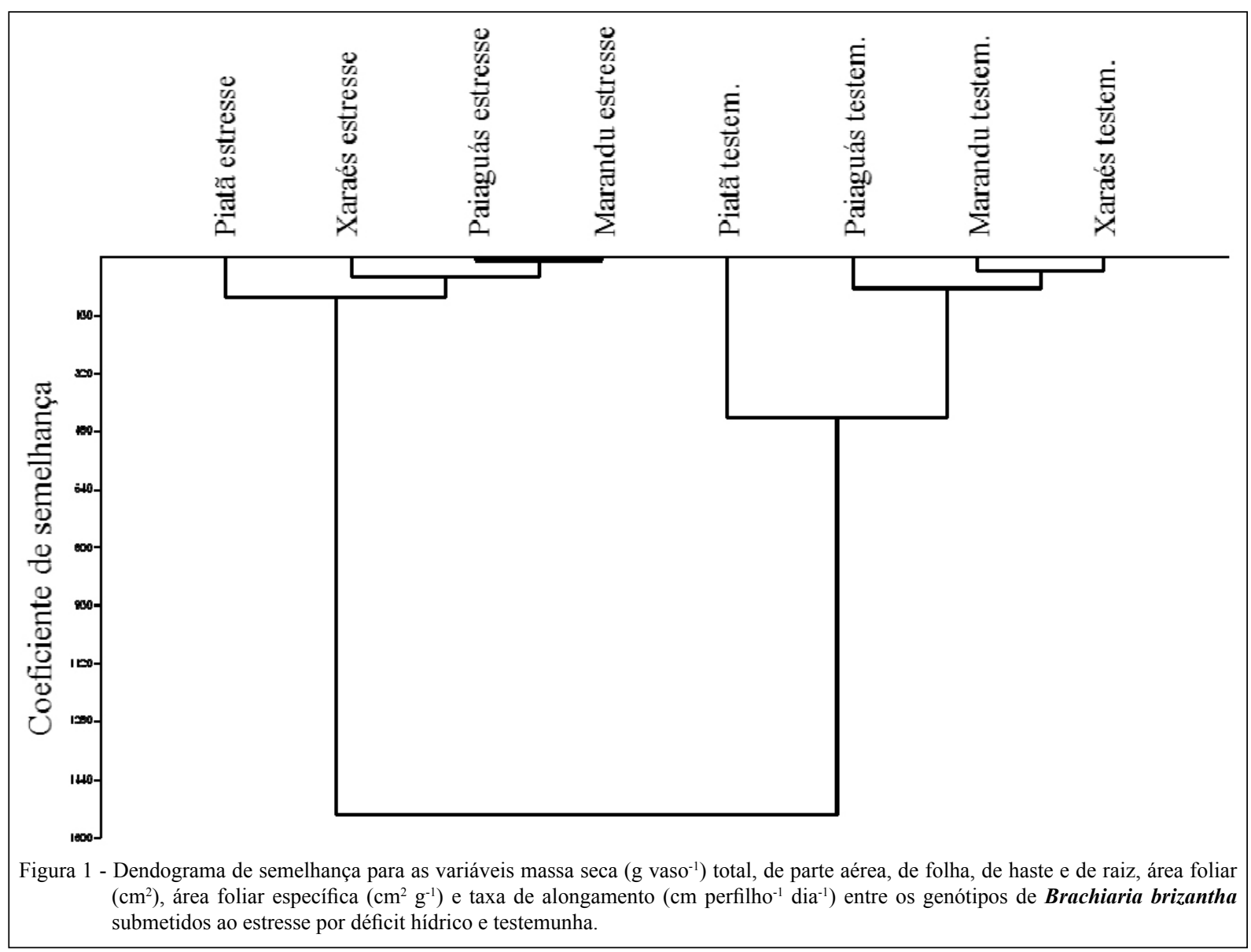

Ciência Rural, v.45, n.5, mai, 2015. 


\section{CONCLUSÃO}

As cultivares da espécie $\boldsymbol{B}$. brizantha utilizadas nesse estudo se apresentaram com comportamento semelhante quando submetidas ao estresse ocasionado pela deficiência hídrica em ambiente de casa de vegetação. A cultivar 'BRS Piatã' foi genótipo que se destacou com as menores reduções de desenvolvimento em comparação a testemunha.

\section{AGRADECIMENTOS}

ÀFundaçãodeAmparoàPesquisadoEstadodeSãoPaulo (Fapesp) pela bolsa de iniciação científica e pelo auxílio financeiro.

\section{REFERÊNCIAS}

BASTOS, E.A. et al. Identification of cowpea genotypes for drought tolerance. Revista Ciência Agronômica, v.42, p.100107, 2011. Disponível em: <http://dx.doi.org/10.1590/S180666902011000100013>. Acesso em: 21 fev. 2013. doi 10.1590/ S1806-66902011000100013.

BENNETT, J.M.; SULLIVAN, C.Y. Effect of water stress preconditioning on net photosynthetic rate of grain Sorghum. Photosynthetica, v.15, n.3, p.330-337, 1981.

BRAY, E.A. et al. Responses to abiotic stresses. In: BUCHANAN, B.B. Biochemistry \& molecular biology of plants. Rockville: American Society of plant physiologists, 2000. 1367p.

COSTA, K.A. de P.C. et al. Efeito da estacionalidade na produção de matéria seca e composição bromatológica da Brachiaria brizantha cv. 'Marandu'. Ciência Animal Brasileira, v.6, p.187-193, 2005.

DUQUE, A.S. et al. Abiotic stress responses in plants: unraveling the complexity of genes and networks to survive. In: VAHDATI, K.; LESLIE, C. Abiotic stress - plant responses and applications in agriculture. Croatia, Rijeka: Tech, 2013. p.49-102.

GUENNI, O. et al. Responses to drought of five Brachiaria species. I. Biomass production, leaf growth, root distribuition, water use and forage quality. Plant and Soil, v.243, p.229-241, 2002.

HAMMER, Ø. et al. Paleontological statistics software package for education and data analysis. Palaeontologia Electronica, v.4, n. 1, 9p, 2001.
IBGE (INSTITUTO BRASILEIRO DE GEOGRAFIA E ESTATÍSTICA), 2006. Disponível em: <http://www.ibge.gov.br>. Acesso em: 14 de agosto de 2012.

KELLER-GREIN, G. et al. Natural variation in Brachiaria and existing germplasm collections. In: MILES, J.W. Brachiaria: biology, agronomy, and improvement. Cali: CIAT / Brasília: Embrapa-CNPGC, 1996. p.106-123.

LITTELL, R.C. et al. Sas for mixed models. 2.ed. Cary: SAS Institute, 2006. 813p.

MALAVOLTA, E. Elementos de nutrição mineral de plantas. Piracicaba: Ceres, 1980. 215p.

LUDLOW, M.M.; NG, T.T. Effect of water deficit on carbon dioxide exchange and leaf elongation rate of Panicum maximum var. trichoglume. Australian Journal of Plant Physiology, v.3, n.3, p.401-413, 1976.

MATTOS, J.L.S. de et al. Crescimento de espécies do gênero Brachiaria sob déficit hídrico em casa de vegetação. Revista Brasileira de Zootecnia, v.34, n.3 p.746-754, 2005.

MELO, S.P. de et al. Silicon accumulation and water déficit tolerance in Brachiaria grasses. Scientia Agricola, v.60, n.4, p.755-759, 2003.

PEDREIRA, C.G.S. et al. Forrageiras Brachiaria, Panicum e Cynodon. In: MONTEIRO, J.E.B.A. Agrometeorologia dos cultivos, o fator meteorológico na produção agrícola. Brasília: INMET, 2009. p.427-447.

SILVA, M. de A. et al. Melhoramento para eficiência no uso da água. In: FRITSCHE-NETO, R.; BORÉM, A. Melhoramento de plantas para condições de estresses abióticos. Viçosa: UFV, 2011. p.127-149.

VARSHNEY, R.K. et al. Genomics and physiological approaches for root trait breeding to improve drought tolerance in chickpea (Cicer arietinum L.). Root Genomics, v.10, p.213-222, 2011.

VALLE, C.B. et al. Gênero Brachiaria. In: FONSECA, D.M.; MARTUSCELLO, J.A. Plantas Forrageiras. Viçosa: UFV, 2011. p.30-77.

XOCONOSTLE-CAZARES, B. et al. Drought tolerance in crop plants. American Journal of Plant Physiology, v.5, n.5, p.241-256, 2010.

ZHENG, H.G. et al. Quantitative trait loci for root penetration ability and root thickness in rice: comparison of genetic backgrounds. Genome, v.43, p.53-61, 2000. 